\title{
HABILIDADES SOCIAIS DE MÃES DE JOVENS E ADULTOS COM SÍNDROME DE DOWN ${ }^{1}$
}

\author{
HABILIDADES SOCIALES DE MADRES JÓVENES Y ADULTAS CON SÍNDROME \\ $D E D O W N$
}

\author{
SOCIAL SKILLS OF MOTHERS OF YOUTH AND ADULTS WITH DOWN \\ SYNDROME
}

\author{
Tatiane Cristina Rodrigues LESSA ${ }^{2}$ \\ Márcia Duarte GALVANI ${ }^{3}$
}

RESUMO: O contexto de trabalho requer relações interpessoais complexas e em pessoas com deficiência esse aspecto pode ser um desafio. Como a família desempenha importante papel no ensino e manutenção dessas relações elegeu-se, para o presente estudo, mães de jovens e adultos com Trissomia 21 a fim de entender como as habilidades sociais destas podem se relacionar com a trajetória de vida de seus filhos. Participaram da pesquisa cinco mães de jovens e adultos que estavam no mercado de trabalho. Como instrumento de coleta de dados utilizou-se o inventário de habilidades sociais e um questionário. Os resultados pontuaram bons repertórios de habilidades sociais em três mães. Quanto à trajetória de vida, todas as mães receberam o diagnóstico após o nascimento dos filhos, os quais realizaram terapias com outros profissionais. As mães relataram que seus filhos se comunicam de maneira satisfatória, apesar de terem apresentado atraso na linguagem, e a maioria frequentou escola regular. Nos aspectos de interação social foi relatado que os jovens e adultos não apresentam dificuldades. Considera-se que o presente estudo tenha contribuído como sugestão para futuras intervenções com essa população.

PALAVRAS-CHAVE: Trissomia 21. Síndrome de Down. Mães. Habilidades Sociais. Mercado de Trabalho.

RESUMEN: El contexto laboral requiere relaciones interpersonales complejas y en las personas con discapacidad este aspecto puede ser un desafio. Dado que la familia juega un papel importante en la enseñanza y el mantenimiento de estas relaciones, las madres de jóvenes y adultos con trisomía 21 fueron elegidas para el presente estudio con el fin de comprender cómo sus habilidades sociales pueden relacionarse con la trayectoria de vida de sus hijos. Participaron de la investigación cinco madres de jóvenes y adultos que se encontraban en el mercado laboral. Como instrumento de recolección de datos se utilizó un inventario de habilidades sociales y un cuestionario. Los resultados obtuvieron buenos

\footnotetext{
${ }^{1}$ Pesquisa com Parecer Consubstanciado do CEP - CAAE: 68948817.1.0000.5504

${ }^{2}$ Universidade Federal de São Carlos - (UFSCar), São Carlos - SP - Brasil. Doutora pelo Programa de Pósgraduação em Educação Especial da UFSCar. ORCID: https://orcid.org/0000-0002-5675-4616. E-mail: taticrisrl@hotmail.com

${ }^{3}$ Universidade Federal de São Carlos - (UFSCar), São Carlos - SP - Brasil. Docente no Programa de Pósgraduação em Educação Especial da UFSCar. ORCID: https://orcid.org/0000-0003-1092-746X. E-mail: marciaduar@yahoo.com.br
} 
repertorios de habilidades sociales en tres madres. En cuanto a la trayectoria de vida, todas las madres recibieron el diagnóstico luego del nacimiento de sus hijos, quienes fueron sometidos a terapias con otros profesionales. Las madres informaron que sus hijos se comunican satisfactoriamente a pesar de haber retrasado el lenguaje y la mayoría asistía a la escuela regular. En los aspectos de interacción social se informó que jóvenes y adultos no tienen dificultades. Se considera que el presente estudio ha contribuido a la sugerencia de futuras intervenciones con esta población.

PALABRAS CLAVE: Trisomía 21. Síndrome de Down. Madres. Habilidades sociales. Mercado de trabajo.

ABSTRACT: The work context requires complex interpersonal relationships and in people with disabilities this aspect can be a challenge. As the family plays an important role in teaching and maintaining these relationships, mothers of young people and adults with Trisomy 21 were chosen for the present study to understand how their social skills can relate to their children's life trajectory. Five mothers of young people and adults who were in the labor market participated in the research. As a data collection instrument, an inventory of social skills and a questionnaire were used. The results scored good repertoires of social skills in three mothers. As for the life trajectory, all mothers received the diagnosis after the birth of their children, who underwent therapies with other professionals. Mothers reported that their children communicate satisfactorily, despite having delayed language, and most attended regular school. In the aspects of social interaction, it was reported that young people and adults have no difficulties. The present study is considered to have contributed to the suggestion of future interventions with this population.

KEYWORDS: Trisomy 21. Down syndrome. Mothers. Social skills. Labor market.

\section{Introdução}

No desenvolvimento interpessoal a capacidade de estabelecer e manter interações sociais simultaneamente produtivas e satisfatórias diante de diferentes interlocutores, situações e demandas é de suma importância. Tal capacidade pode ser um desafio no contexto de pessoas com deficiência, isso porque alguns tipos de deficiência têm esse desenvolvimento deficitário e/ou insuficiente, o que gera, por sua vez, entraves no dia a dia dessas pessoas.

Um sinalizador confiável de como esse desenvolvimento interpessoal se dá pode ser a família, isso porque, normalmente, é nesse contexto que ocorrem os principais relacionamentos interpessoais. Assim, a união de familiares de pessoas com deficiência e seus relacionamentos interpessoais merecem intervenções e pesquisas que visem auxiliá-los em seus mais diferentes contextos (familiares, de trabalho, sociais, entre outros). Partindo dessa necessidade, a população elegida para o presente estudo foi a de mães de jovens e adultos com 
Trissomia 21, visto que suas habilidades sociais serão de grande importância na formação interpessoal de quaisquer sujeitos (DEL PRETTE; DEL PRETTE, 2013).

As habilidades sociais (HS) podem ser compreendidas, segundo Del Prette e Del Prette (2017), como um construto descritivo de comportamentos sociais valorizados em uma cultura e que, quando desempenhados adequadamente, tem alta probabilidade de fornecer resultados positivos tanto para a pessoa como para sua comunidade. Os comportamentos caracterizados como HS, segundo Del Prette e Del Prette (2017), podem ser classificados e agrupados em diferentes classes e subclasses. Essa classificação e agrupamento levam em conta aspectos formais e funcionais, ou seja, gestos, expressão facial, corporal etc., e sua função em uma dada situação.

Del Prette e Del Prette (2017, p. 27) sugerem um portfólio de HS cuja premissa é listar as classes e subclasses "relevantes e pertinentes às tarefas e papéis sociais bem como à etapa de desenvolvimento". Essa separação é didática e norteia a identificação dessas classes, sendo elas: 1. Comunicação; 2. Civilidade; 3. Fazer e manter amizade; 4. Empatia; 5. Assertivas; 6. Expressar solidariedade; 7. Manejar conflitos e resolver problemas interpessoais; 8. Expressar afeto e intimidade; 9. Coordenar grupo e; 10. Falar em público.

O aprendizado dessas HS ocorre em diferentes meios culturais, sendo a família um dos principais (DEL PRETTE; DEL PRETTE, 2017). Essa, em pessoas com deficiência, será de suma importância uma vez que, segundo Goitein e Cia (2011), o envolvimento, cuidado e estimulação serão essenciais para o seu desenvolvimento. Na família os padrões culturais são transmitidos, normalmente, pelo estabelecimento de regras, manejo de consequências e oferecimento de modelos comportamentais dos pais e/ou cuidadores.

Beidel, Turner e Morris (2000) destacam que algumas HS são consideradas de extrema relevância em qualquer contato social, como sorrir, fazer contato olho a olho, perguntar e responder, dar e reconhecer elogios, entre outros. Em populações com deficiência esses comportamentos não são diferentes, mas normalmente, os estudos que envolvem esses padrões comportamentais ocorrem em crianças e adolescentes como, por exemplo, os estudos de Mancini, Silva, Gonçalves e Martins (2003), Bonomo, Garcia e Rosseti (2009), Angélico e Del Prette (2011), Rodrigues, Santos e Carlino (2014).

Talvez esse fato se deva à existência de instrumentos de medidas em HS cujo respondente, no caso de crianças e adolescentes, podem ser os responsáveis ou professores. Poucos estudos englobam a população adulta como o de Rodrigues, Bianchi, Aissa, Souza e Galvani (2019) pois, no caso de adultos com deficiência, a medida dessas habilidades torna-se mais complexa, pois os instrumentos de HS para a populações adultas são de autorrelato e o 
instrumento pode inferir situações abstratas que seriam de difícil compreensão para algumas populações, como aquela com Trissomia 21. Elliott e Gresham (2008) trazem alguns instrumentos para populações com deficiência, mas em âmbito internacional e, conforme indicaram Quitério, Nunes e Gerk (2020) que trazem de maneira preliminar uma possibilidade de instrumento para adultos sem fala articulada, esses instrumentos ainda estão distantes de nossa realidade cultural.

Portanto considera-se que os estudos das HS em jovens e adultos com deficiência e, especialmente aqueles que já estão no mercado de trabalho, são de suma importância pois, como evidencia o estudo de Pereira e Batanero (2009), é a partir do ingresso no mundo do trabalho que as pessoas com deficiência são inseridas em diversas características sociais desafiadoras, como a necessidade de convívio, superação de dificuldades, participação ativa na sociedade, entre outras. Também se destaca que o ambiente de trabalho proporcionará características importantes no que diz respeito, por exemplo, à aquisição ou aperfeiçoamento das habilidades sociais e, ainda, quanto ao aspecto de maturidade profissional.

Nesse sentido, relacionando-se a temática das HS e do ambiente de trabalho e, ainda, corroborando com a ideia de que cada tipo de deficiência trará consigo uma especificidade, elegeu-se para esse estudo a Trissomia 21 (T21). Adotou-se a nomenclatura Trissomia 21 para referência a síndrome de Down, apesar do epônimo Síndrome de Down, em homenagem ao professor John Langdon Down. Em 1980, o professor Jérôme Lejeune referenciou que a intenção da homenagem foi transparente, mas lembrou que, até o fim da década de 1950, o idioma que predominava era o Francês e, a partir de 1960, passou a ser o Inglês. Em virtude de traduções inadequadas para Down syndrome, de forma lamentável leigos e mesmo profissionais, passaram a escrever a palavra "Síndrome" com a primeira letra maiúscula e down começando com minúsculo, dando uma conotação pejorativa e ignorando a referência a um sobrenome. Por essa justificativa, o professor Lejeune manifestou intenção em mudar tal nomenclatura, justificando, assim a proposta do termo Trissomia 21 (MUSTACCHI; SALMONA; MUSTACCHI, 2017).

De acordo com as Diretrizes de atenção à pessoa com síndrome de Down, a T21 é uma alteração genética decorrente da presença de um cromossomo 21 extra na célula humana e a principal causa de deficiência intelectual nessa população. A presença do cromossomo 21 extra na constituição genética determina características físicas específicas e atraso em diferentes áreas do desenvolvimento (BRASIL, 2013).

Além da deficiência intelectual que, segundo o Manual Diagnóstico e Estatístico de Transtornos Mentais DSM-V (APA, 2014), é definida como um transtorno iniciado no 
período do desenvolvimento e marcado por déficits funcionais, tanto intelectuais quanto adaptativos, nos domínios conceitual, social e prático (APA, 2014), o atraso na linguagem é comum nessa população. Essa pode, segundo Quitério (2009), comprometer a aquisição de sistemas simbólicos e, consequentemente, o desenvolvimento das HS.

Além desses aspectos, Soresi e Nota (2000) afirmam que a literatura aponta para uma tendência a pouca interação social nesse público quando comparado às pessoas com desenvolvimento típico e que esse repertório deficitário pode resultar negativamente na adaptação e interação social da vida adulta, em especial no mundo do trabalho.

Por isso, Angonese, Boueri e Schmidt (2015) sugerem estudos com grupos de trabalhadores com DI com focos diferentes. As autoras evidenciam a necessidade de desenvolvimento de estratégias de orientação profissional e de carreira para a população com deficiência, como forma de contribuir, efetivamente, na inserção e permanência destes no mercado de trabalho, tendo como foco propiciar condições de aprendizagem e melhor desenvolvimento à essa população. Contudo, acrescenta-se a necessidade de olhar para as habilidades sociais dos familiares de pessoas com deficiência que chegaram ao mercado de trabalho. Isso porque, como alguns estudos identificaram, o empoderamento de famílias de crianças com deficiência correlaciona-se positivamente com algumas HS dessas (ARAGON; COSTA; CIA, 2019), seria necessário compreender como as HS dessas famílias se desenvolveram pois, conforme destacou Papay e Bambara (2014), essas também têm importante papel na inserção, sucesso e permanência de pessoas com deficiência intelectual no contexto do trabalho.

Assim, a relevância da temática proposta pelo presente estudo justifica-se pela sugestão de que mães com bons repertórios de habilidades sociais influenciarão positivamente nas habilidades sociais de seus filhos e, consequentemente, na melhor adaptabilidade dessas pessoas com deficiência ao longo da vida, especialmente no mercado de trabalho. Nesse sentido, dois questionamentos norteiam esse estudo: Como se caracteriza o repertório de habilidades sociais em mães de jovens com T21 que já estão inseridos no mercado de trabalho? Qual relação as habilidades sociais das mães têm com a trajetória de vida ${ }^{4}$ de seus filhos?

${ }^{4}$ A trajetória de vida pode ser descrita como um conjunto de eventos que fundamentam a vida de uma pessoa. Normalmente é determinada pela frequência dos acontecimentos, pela duração e localização dessas existências ao longo de uma vida (BORN, 2001). 
Frente a esses questionamentos, este trabalho tem como objetivo analisar qual o repertório de habilidades sociais de mães de jovens e adultos com T21 que já estão inseridos no mercado de trabalho e relacionar essas habilidades com a trajetória de vida de seus filhos.

\section{Metodologia}

A presente pesquisa é de caráter descritivo (COZBY, 2003), cumpriu todos os critérios éticos para pesquisa com seres humanos e teve parecer favorável no Comitê de Ética em Pesquisa para Seres Humanos (CAAE: 68948817.1.0000.5504). A mesma ocorreu em uma instituição de apoio a pessoas com T21 em uma cidade do interior do estado de São Paulo.

Participaram do estudo cinco mães de jovens e adultos com T21. Essas foram classificadas como M1, M2, M3, M4 e M5 e suas idades variaram entre 48 e 62 anos. Quanto ao grau de escolaridade, duas possuem o ensino médio e três o ensino superior.

Quanto aos jovens e adultos com T21, filhos das participantes entrevistadas, as idades variaram entre 21 e 38 anos, dois eram do sexo masculino (F1 e F5) e 3 do sexo feminino (F2, F3 e F4). Todos os filhos foram diagnosticados com T21 e encontravam-se empregados no mercado de trabalho a mais de um ano.

Destaca-se que, apesar da pesquisa ter sido realizada apenas com as mães de jovens e adultos com SD, os filhos serão mencionados em diversos momentos e, por isso, optou-se por classificá-los como F1, F2, F3, F4 e F5. A Tabela 1 traz a síntese dos dados de classificação das participantes e de seus filhos.

Tabela 1. Caracterização dos participantes

\begin{tabular}{|c|c|c|c|c|c|}
\hline $\begin{array}{c}\text { Participante } \\
\text { (mãe) }\end{array}$ & $\begin{array}{c}\text { Grau de } \\
\text { Escolaridade }\end{array}$ & $\begin{array}{c}\text { Filho } \\
\text { (com T21) }\end{array}$ & Idade & $\begin{array}{c}\text { Tipo de } \\
\text { Escolarização }\end{array}$ & $\begin{array}{c}\text { Local de Trabalho } \\
\text { e Função }\end{array}$ \\
\hline M1 & $\begin{array}{l}\text { Superior } \\
\text { Completo }\end{array}$ & $\mathrm{F} 1$ & $\begin{array}{c}27 \\
\text { anos }\end{array}$ & $\begin{array}{l}\text { Ensino } \\
\text { Regular }\end{array}$ & Varejão/reposição \\
\hline M2 & $\begin{array}{l}\text { Médio } \\
\text { completo }\end{array}$ & $\mathrm{F} 2$ & $\begin{array}{c}21 \\
\text { anos }\end{array}$ & $\begin{array}{l}\text { Ensino } \\
\text { Regular }\end{array}$ & Farmácia/repositor \\
\hline M3 & $\begin{array}{c}\text { Médio } \\
\text { Completo }\end{array}$ & F3 & $\begin{array}{c}29 \\
\text { anos }\end{array}$ & $\begin{array}{l}\text { Ensino } \\
\text { Regular }\end{array}$ & Farmácia repositor \\
\hline M4 & $\begin{array}{l}\text { Superior } \\
\text { Completo }\end{array}$ & F4 & $\begin{array}{c}38 \\
\text { anos }\end{array}$ & $\begin{array}{c}\text { Instituição } \\
\text { Especializada }\end{array}$ & $\begin{array}{l}\text { Centro Unimed de } \\
\text { Qualidade de Vida }\end{array}$ \\
\hline
\end{tabular}




\begin{tabular}{|c|c|c|c|c|c|}
\hline & & & & /recepção \\
\hline \multirow{2}{*}{ M5 } & $\begin{array}{c}\text { Superior } \\
\text { Completo }\end{array}$ & F5 & 22 & Ensino & $\begin{array}{c}\text { Laboratório de } \\
\text { Análises Clínicas / } \\
\text { recepção }\end{array}$ \\
\hline
\end{tabular}

Fonte: Autoria própria

Como instrumento de coleta de dados, foram utilizados o Inventário de Habilidades Sociais 2 - IHS2-Del Prette (DELPRETTE; DEL PRETTE, 2018) e um roteiro de anamnese. O IHS2-Del-Prette é um instrumento de autorrelato para avaliação de habilidades sociais, analisado e aprovado pelo Conselho Federal de Psicologia. O instrumento permite caracterizar o desempenho social em diferentes situações possibilitando o diagnóstico em diferentes contextos: clínica, educacional, seleção pessoal, entre outros. O respondente deve estimar a frequência com que reage da forma sugerida em cada item, considerando o total de vezes que se encontrou na situação descrita, e estimar a frequência de sua resposta em escala tipo Likert, com cinco pontos, variando de 0-2 (nunca ou raramente) a 9-10 (sempre ou quase sempre). Os itens produzem um ESCORE TOTAL $(\alpha=0,944)$ e escores em cinco fatores: F1 Conversação Assertiva $(\alpha=0,934)$; F2 - Abordagem Afetivo-sexual $(\alpha=0,774)$; F3 Expressão de Sentimento Positivo $(\alpha=0.984)$; F4 - Autocontrole/Enfrentamento $(\alpha=0,840)$ e F5 - Desenvoltura Social $(\alpha=0,840)$. O instrumento pode ser utilizado em populações cuja faixa etária abranja dos 18 aos 59 anos sendo a apuração específica para duas faixas: 18-38 anos e 39-59 anos. O roteiro de anamnese foi construído com base em Brasil (2013), totalizando 28 questões abertas e, para o presente artigo, utilizou-se o recorte dos seguintes eixos: 1. Diagnóstico e Intervenção precoce; 2. Escolarização e Linguagem e; 3. Aspectos de Interação Social.

Como procedimento de coleta de dados, primeiramente, entrou-se em contato com as mães de jovens e adultos com T21 que estavam inseridos no mercado de trabalho. Em seguida foram agendados dias e horários com as participantes, conforme conveniência de cada uma, na instituição que já frequentavam. No dia combinado para a coleta as mães apresentavam-se na instituição e era explicado pela pesquisadora os objetivos da pesquisa e, caso optassem por participar, as mães assinavam o Termo de Consentimento Livre e Esclarecido da pesquisa. Em seguida era apresentado o IHS2-Del Prette, após isso a pesquisadora iniciava a gravação das respostas do roteiro de anamnese. Para a análise dos dados do IHS2-Del Prette, foi utilizado o crivo de correção do instrumento e, a partir do mesmo, a classificação quanto as suas HS. Para os dados provenientes da anamnese foi realizada a análise de conteúdo com a 
categorização pré-determinada a partir dos blocos temáticos conforme sugerido por Franco (2008).

\section{Resultados e Discussão}

Os resultados estão apresentados em dois tópicos: (a) habilidades sociais das mães entrevistadas e (b) Trajetória de vida dos filhos.

\section{a) Habilidades Sociais das mães dos jovens e adultos com T21}

Os resultados obtidos nos escores de habilidades sociais pelo IHS2-Del Prette, aplicado, nas mães estão descritos na tabela a seguir.

Tabela 2. Caracterização das habilidades sociais das mães participantes da pesquisa quanto ao escore geral e fatorial

\begin{tabular}{|c|c|c|c|c|c|c|}
\hline PARTICIPANTE & $\begin{array}{c}\text { ESCORE } \\
\text { GERAL }\end{array}$ & F1 & F2 & F3 & F4 & F5 \\
\hline M1 & 91 & 45 & 9 & $30^{* * *}$ & $10^{* *}$ & $18^{* * *}$ \\
\hline M2 & $72^{* *}$ & $36^{* * *}$ & 8 & $18^{*}$ & $12^{* *}$ & $6^{*}$ \\
\hline M3 & $82^{* * *}$ & $38^{* * *}$ & $0 *$ & 32 & $12^{* *}$ & 20 \\
\hline M4 & $63^{*}$ & $23^{* *}$ & $0^{*}$ & $26^{*}$ & $15^{* * *}$ & 21 \\
\hline M5 & 94 & $36^{* * *}$ & 9 & $30^{* * *}$ & 16 & 22 \\
\hline
\end{tabular}

Legenda: F1- Conversação Assertiva; F2- Abordagem Afetivo-sexual; F3- Expressão de Sentimento Positivo; F4- Autocontrole/Enfrentamento; F5 - Desenvoltura Social

Valores de Referência (mínimo-máximo): 39 a 59 anos (sexo feminino - ESCORE GERAL = 38,78-115; F1 = $2,39-51 ; \mathrm{F} 2=0-12 ; \mathrm{F} 3=17-32 ; \mathrm{F} 4=2-20 ; \mathrm{F} 5=5-24$ )

* Repertório inferior de habilidades sociais. Indicativo de déficit e necessidade de treinamento de habilidades sociais, especialmente naquelas subescalas e itens mais críticos para ajustamento pessoal e profissional ** Repertório médio inferior de habilidades sociais, com resultados abaixo da média em grande parte dos itens. Indicativo de necessidade de treinamento de habilidades sociais, especialmente naquelas subescalas e itens mais críticos para o ajustamento pessoal e profissional

*** Bom repertório de habilidades sociais, com resultado dentro da média para a maior parte dos itens ou equilíbrio entre recursos e déficits nesses itens e subescalas em que aparecem. Bom repertório de habilidades sociais, com resultado dentro da média para a maior parte dos itens ou equilíbrio entre recursos e déficits nesses itens e subescalas em que aparecem.

Fonte: Própria Autoria 
Segundo dados da Tabela 2, os escores gerais obtidos pelo IHS2-Del Prette, a M1 e M5 apresentaram repertório elaborado de $\mathrm{HS}^{5}$, M3 um bom repertório de HS, M2 um repertório médio inferior de HS e M4 um repertório inferior de habilidades sociais com indicativo de déficit e necessidade de Treinamento de HS. Acredita-se que, em relação as mães que apresentam bons escores de habilidades sociais (M1, M3 e M5), a própria trajetória das mães possa ter influenciado nos resultados uma vez que, conforme verificado pela anamnese, elas precisaram buscar diferentes tipos de atendimentos para seus filhos e, possivelmente, demonstrar boa resiliência para superar a condição de deficiência deles. Além disso, sugere-se que o bom repertório também influenciou para que os filhos estejam inseridos no mercado de trabalho, pois as experiências familiares de pessoas com deficiência no mercado de trabalho têm influência familiar, conforme demonstrou o estudo de Augusto (2020).

Em relação aos escores fatoriais, percebe-se bons repertórios de HS no Fator 1, correspondente à conversação assertiva em todos os participantes, exceto por M4. Destaca-se que tal habilidade é de suma importância para os pais de pessoas com deficiência que, na maioria das vezes, precisam lutar pelos direitos de seus filhos e buscar por serviços de apoio ao longo da vida dos mesmos (AUGUSTO, 2020). Isso também é importante para os filhos que ingressaram no mercado de trabalho, uma vez que todos os cargos desempenhados pelos participantes com T21 no presente estudo referem-se a cargos que se relacionam diretamente com o público.

No Fator 2, abordagem afetivo-sexual, as participantes M3 e M4 apresentaram repertório inferior de HS com indicativo de treinamento de habilidades sociais (THS). É importante notar que a pesquisa de Silva, Paixão e Villela (2016) já havia demonstrado que as mães de pessoas com T21 estão conscientes da sexualidade de seus filhos, mas não a percebem no dia a dia. Talvez a não percepção possa relacionar-se ao fato de não reconhecerem a própria sexualidade e, portanto, também a de seus filhos. Sugere-se, portanto, que futuras pesquisas e intervenções possam ser realizadas no sentido de verificar a real existência dessa dificuldade, uma vez que a amostra desse estudo é pequena podendo não corresponder a características gerais dessas mães. Em contrapartida, caso seja evidenciado essa dificuldade, sugere-se a criação de programas que possam auxiliar essas mães em sua própria sexualidade e, consequentemente, na de seus filhos.

5 Ressalta-se que as nomenclaturas classificatórias utilizadas para os repertórios de habilidades sociais encontrados pelos participantes são as nomeadas pelo próprio instrumento de referência utilizado e validado pelo Conselho Federal de Psicologia, no caso o IHS2-Del Prette. 
No Fator 3, expressão de sentimento positivo, as participantes M2 e M4 apresentaram repertórios inferiores de HS com indicativo de THS. A expressão de sentimentos já vem sendo evidenciada na literatura como uma dificuldade encontrada em familiares de pessoas com deficiência em diversos contextos: irmãos (ALVES; SERRALHA, 2019), momento do diagnóstico (SILVA; LIMA, 2017), entre outros. Tal dado sugere que sejam realizadas intervenções focalizadas na expressão de sentimento dos familiares, em especial das mães, para que possam, dessa forma, auxiliar seus filhos com deficiência na expressão de sentimentos, uma vez que a literatura, conforme destacou o estudo de Rooke, Almeida e Mejia (2017), mostra que as intervenções têm sido no sentido de orientar ou apoiar as famílias de pessoas com deficiência.

No Fator 4, autocontrole e enfrentamento, todos os participantes tiveram os escores medianos ou acima da média. Possivelmente tal fato deva-se a essas famílias estarem constantemente expostas a situações em que precisam utilizar essa habilidade social, uma vez que se sabe que o contexto da pessoa com deficiência exige de seus familiares enfrentamento de situações adversas e, muitas vezes, estressantes. Esse dado corrobora os achados no estudo de Aragon, Costa e Cia (2019) em que foram encontradas correlações positivas entre o empoderamento de pais de pessoas com deficiência e suas habilidades sociais.

No Fator 5, desenvoltura social, apenas a M2 obteve escore indicativo de THS. As demais mães pontuaram bons escores de HS. Tal dado é sugestivo para futuras pesquisas, uma vez que contrariou o estudo de Spinazola, Cia, Azevedo e Gualda (2018). No estudo das autoras supracitadas, as mães de pessoas com Trissomia 21 alegaram precisar de mais informações sobre a maneira de falar com o filho e, nesse sentido, vai de encontro com bons repertórios de habilidades, conforme encontrado na presente pesquisa. Por isso, sugere-se uma melhor compreensão de quais são as reais dificuldades e facilidades dessas mães quanto aos aspectos de desenvoltura social, a fim de produzir futuras intervenções que possa beneficiálas.

\section{b) Trajetória de vida de seus filhos}

Os dados provenientes da anamnese foram agrupados nas categorias: 1. Diagnóstico e Intervenção precoce; 2. Escolarização e Linguagem e; 3. Aspectos de Interação Social descritos a seguir. 


\section{Diagnóstico e Intervenção precoce}

Nessa categoria, as mães foram questionadas quanto ao momento do diagnóstico e se seus filhos haviam sido encaminhados para algum tipo de atendimento ou programas de estimulação precoce. Em relação ao diagnóstico, todas as mães relataram que os filhos foram diagnosticados após o nascimento, sendo que M1 e M5 relataram terem recebido a confirmação pelo exame de cariótipo apenas 40 dias após o parto. Segundo a Diretrizes de atenção à pessoa com síndrome de Down após o nascimento, o diagnóstico da T21 é indicado pela aparência física da criança e é confirmado quando se encontra uma cópia extra do cromossomo 21 em uma amostra sanguínea (BRASIL, 2013).

Em decorrência do diagnóstico, todas as participantes indicaram a participação de seus filhos em programas de estimulação desde o nascimento, todas iniciando esses por orientações médicas. Esses programas normalmente envolviam atendimento em fonoaudiólogos, terapeutas ocupacionais e fisioterapeutas, a maioria alegou tempo estimado de oito anos, exceto para fonoaudiólogo visto que alguns adultos (F3 e F5) ainda realizam atendimento. As experiências dessas mães foram contrárias ao que demonstrou o estudo de Ribeiro (2017), em que mães relataram experiências negativas com profissionais de saúde no atendimento e diagnóstico com os filhos.

Somente M1 indiciou um tipo de estimulação diferente, o Bobath. Segundo Peres, Ruedell e Diamante (2009) esse método tem como "objetivo incentivar e aumentar a habilidade da criança de mover-se funcionalmente da maneira mais coordenada possível" ( $p$. 29).

\section{Escolarização e Linguagem}

Nessa categoria as mães foram questionadas em relação à escolarização, se seus filhos haviam frequentado escola, de qual tipo e com quantos anos haviam ingressado. Segundo os relatos, apenas F4 frequentou instituição especializada, os outros quatro (F1, F2, F3 e F5) frequentaram a escola regular desde a Educação Infantil, com variação das idades iniciais, começando entre 3 e 5 anos.

Nos aspectos de linguagem, as falas das mães foram ao encontro do que a literatura mostra sobre as dificuldades de fala em pessoas com T21 (SENO; GIACHETI; MORETTIFERREIRA, 2014). Quando questionadas sobre a idade de fala de seus filhos (palavras, frase e frase complexa), se houve atraso no aparecimento, se seus filhos respondem quando chamados e como é a articulação e compreensão na pronúncia da fala por pessoas estranhas, 
as mães relataram aspectos bastante parecidos: M1, M2 e M4 destacaram que os filhos não apresentaram atrasos na fala simples, como dizer a palavra "água". Já nas falas complexas, como elaboração de frase "eu quero água", apenas M2 e M4 relataram a ausência de dificuldade em seus filhos; M3 e M5 relataram que seus filhos, F3 e F5, apresentaram atraso na fala de maneira geral, sendo que M3 relatou que a fala de F3 ocorreu após os 6 anos de idade e M5 não soube mensurar a data precisa. Tais aspectos corroboram o que é encontrado na literatura, conforme destacado por Seno, Giacheti e Moretti-Ferreira (2014).

Nos demais aspectos de linguagem questionados (se responde quando chamado, se responde a qualquer pessoa, sobre a articulação na fala e se pessoas estranhas compreendem seus filhos), as mães foram unânimes em responder que a fala depende muito do interesse e do assunto que está sendo tratado. Apenas M3 e M5 disseram que, apesar de pessoas estranhas normalmente compreenderem a fala de seus filhos, às vezes, há uma dificuldade.

Outros questionamentos verificados nessa categoria foram quanto ao relato de fatos e/ou histórias e se esses ocorriam sobre temas diversos ou específicos e, ainda, se os filhos expunham as opiniões deles com uso de elementos convincentes em suas justificativas. As mães M1, M4 e M5 relataram que seus filhos sempre narram fatos e histórias com riqueza de detalhes. Também destacaram que há alguma repetição sobre o tema que lhes interessa, mas que, também, ocorrem essas narrações em outras temáticas.

Já as mães M2 e M3 destacaram que é difícil ocorrer relatos de fatos ou histórias, M2 justificou que, normalmente, ela está sempre junto com a filha, não existindo aspectos novos de eventos que ocorreram sobre os quais ainda não tenham conversado. Em contrapartida, acrescentou que no aspecto relativo a dar opiniões e justificar, sua filha, F2 o faz desde a tenra idade. Contrariamente, M3 relatou que dificilmente sua filha dá opiniões sobre suas vontades.

As mães de F3 e F5 relataram que seus filhos apresentaram atraso no desenvolvimento da linguagem corroborando a literatura, conforme cita Lamônica e Ferreira-Vasques (2015). Contudo os escores do IHS2-Del Prette no item desenvoltura social e conversação foram bons, o que sugere questionamentos da influência que essas habilidades podem ter tido nos déficits de seus filhos ou se, nas falas das mães sobre a dificuldade, o que era mencionado eram apenas problemas na dicção ou problemas de outras naturezas. 


\section{Aspectos de Interação Social}

$\mathrm{Na}$ categoria aspectos de interação social, as mães foram questionadas sobre como seus filhos agiam: no fazer e responder perguntas, expressar sentimentos, iniciativa de fazer amizades, buscar auxílio quando necessário, utilização de palavras de civilidade.

Todas as mães relataram que seus filhos não apresentam problemas quanto à iniciativa em elaborar e responder perguntas tanto para pessoas conhecidas como desconhecidas. Também foi unânime na visão das mães a utilização de palavras de civilidade como por favor, obrigada e bom dia por parte de seus filhos em qualquer ambiente.

Quanto à expressão de sentimentos, M1, M2 e M4 relataram que os filhos expressam o que sentem, mas, essa expressão costuma ser feita para pessoas próximas, como familiares. A mãe M3 relatou que a filha é introvertida e emotivamente mais fechada. Já M5 relatou que as vezes o filho expressa seus sentimentos e as vezes não, não há uma constância nesse fato.

Em relação a fazer amizade com facilidade, ter iniciativa em começar uma amizade e comentar sobre situações que agrade ou desagrade (verbal ou gestualmente), M1, M2, M4 e M5 relataram aspectos positivos para todas as interações, ou seja, que os filhos fazem amizade com facilidade, que tem iniciativa para começá-la e que comentam sobre situações que os agradam ou desagradam. Todavia, a mãe M4 incluiu em sua fala uma particularidade que, possivelmente, sua filha esperaria uma dica social para iniciar a amizade, como um sorriso, por exemplo. Bonomo, Garcia e Rossetti (2009) apontam que as pessoas com T21 tem amigos, mas é uma amizade marcada, fundamentalmente, por atitudes de ajuda e de companheirismo em atividades que comumente praticam.

Quanto à busca de auxílio, todas as mães alegaram que os filhos buscam ajuda caso seja necessário. Porém, M3 e M4 acreditam que o pedido de ajuda de seus filhos seja direcionado apenas para pessoas conhecidas e M1, M2 e M5 acreditam que os filhos pedem auxílio a pessoas conhecidas e desconhecidas e acabam encontrando uma forma de sair da situação.

De maneira geral, as mães participantes da pesquisa relataram boas habilidades sociais de civilidade e empatia em seus filhos, especificamente na subclasse refletir sentimentos, questionada nessa pesquisa. Tal dado deveria ser mais bem investigado uma vez que a desejabilidade social dessa questão é elevada (DEL PRETTE; DEL PRETTE, 2013), já que, em nossa cultura, é esperado que as pessoas se cumprimentem, digam bom dia, boa tarde e boa noite, entre outros, e as respostas das mães podem ter sido controladas por essa questão cultural. Alguns estudos têm direcionado situações estruturadas para aferir tais 
comportamentos em pessoas com deficiência, como foi o caso do estudo de Rodrigues, Bianchi, Aissa, Souza e Galvani (2019).

\section{Considerações Finais}

Diante das questões propostas para o presente estudo acredita-se que os objetivos foram atingidos. Isso porque, aferir o repertório de habilidades sociais de mães de jovens e adultos com T21 deu indícios importantes de que essas habilidades podem auxiliar no favorecimento e ganho dessas habilidades por seus filhos, o contrário também pode ocorrer. Nesse aspecto, o estudo trouxe bons direcionamentos de necessidades a serem preenchidas nessa população, como intervenções que foquem na sexualidade de adultos com deficiência ou estudos que possam medir os desempenhos deles em situações reais ou hipotéticas.

Outro destaque obtido na pesquisa foi em relação a habilidade de conversação e desenvoltura social, pois pode-se supor que o contexto do trabalho exige um bom desempenho dessa habilidade, o que, no entanto, não pôde ser verificado, uma vez que os adultos não participaram do preenchimento dos questionários. Por isso sugere-se novos estudos a fim de compreender como esses jovens e adultos com T21, que apresentam dificuldades de dicção, se comunicam e, ainda, como seria a compreensão por seus ouvintes.

De maneira geral, compreende-se que essa pesquisa trouxe avanços importante ao analisar as habilidades sociais de jovens e adultos com T21 e relacioná-las com sua trajetória de vida, o que pode contribuir em futuros estudos que continuem a investigar tais habilidades e/ou realizar intervenções focadas nas lacunas aqui encontradas.

AGRADECIMENTOS: Conselho Nacional de Desenvolvimento Científico e Tecnológico $\mathrm{CNPq}$

\section{REFERÊNCIAS}

ANGÉLICO, A. P.; DEL PRETTE, A. Avaliação do repertório de habilidades sociais de adolescentes com síndrome de Down. Psicologia: Reflexão e Crítica, n. 24, v. 2, p. 207-217. 2011.

ANGONESE, L. S.; BOUERI, I. Z.; SCHMIDT, A. O adulto com deficiência intelectual: concepção de deficiência e trajetória de carreira. Revista Brasileira de Orientação Profissional, n. 16, v. 1, p. 23-34. 2015. 
ALVES, C. M. P.; SERRALHA, C. M. P. Repercussões emocionais em indivíduos que possuem irmãos com deficiência: uma revisão integrativa. Contextos Clínicos, n. 2, v. 12, mai./ago. 2019.

ARAGON, C. A.; COSTA, C. S. L.; CIA, F. Habilidades sociais e empoderamento de pais de crianças pré-escolares do público-alvo da educação especial. Revista Educação Especial, v. 32, Santa Maria, 2019.

\section{ASSOCIAÇÃO AMERICANA DE PSIQUIATRIA. DSM-5 - Manual Diagnóstico e} Estatístico de Transtornos Mentais. Porto Alegre: Artmed, 2014.

AUGUSTO, M. A. M. Experiências de pessoas com deficiência no trabalho: o papel e a importância da família. 2020. Dissertação (Mestrado em Educação). Universidade Estadual Paulista “Júlio de Mesquita Filho" - UNESP, Marília. 2020.

BEIDEL, D. C.; TURNER, S. M.; MORRIS, T. L. Behavioral treatment of childhood social phobia. Journal of Consulting and Clinical Psychology, n. 68, p. 1072-1080. 2000.

BONOMO, L. M. M., GARCIA, A.; ROSSETTI, C. B. O adolescente com síndrome de Down e sua rede de relacionamentos: Um estudo exploratório sobre suas amizades.

Psicologia: Teoria e Pesquisa, n. 11, v. 3, p. 114-130. 2009.

BRASIL. Ministério da Saúde. Secretaria de Atenção à Saúde. Departamento de Ações Programáticas Estratégicas. Diretrizes de atenção à pessoa com Síndrome de Down. 1 ed., 1. reimp. - Brasília: Ministério da Saúde, 2013. 60 p.

COZBY, P. C. Métodos de pesquisa em ciências do comportamento. São Paulo: Atlas. 2003.

DEL PRETTE, A.; DEL PRETTE, Z. A. P. Psicologia das relações interpessoais: vivências para o trabalho em grupo. 10.ed. Petrópolis: Vozes, 2013. 231 p.

DEL PRETTE, A.; DEL PRETTE, Z. A. P. Competência Social e Habilidades Sociais: Manual teórico-prático. Petrópolis: Vozes, 2017.

DEL PRETTE, Z. A. P.; DEL PRETTE, A. Inventário de habilidades sociais 2 (IHS2-DelPrette). São Paulo: Pearson Clinical Brasil, 2018. 120 p.

ELLIOTT, S. N.; GRESHAM, F. M. Social skills intervention guide. Bloomington: Pearson Assessments. 2008.

FRANCO. M. L. P. B. Análise de Conteúdo (2ª ed.). Brasília: Líber Livros Editora. 2008.

GOITEIN, P. C.; CIA, F. Interações familiares de crianças com necessidades educacionais especiais: Uma revisão da literatura nacional. Psicologia Escolar e Educacional (Impresso), v. 15, p. 43-51, 2011.

LAMÔNICA, D. A. C.; FERREIRA-VASQUES, A. T. Habilidades comunicativas e lexicais de crianças com síndrome de Down: reflexões para a inclusão escolar. Revista CEFAC, $n$. 17 , v. 5 , p. $1475-1482,2015$. 
MANCINI, M. C.; SILVA, P. C.; GONÇALVES, S. C; MARTINS, S. M. Comparação do desempenho funcional de crianças portadoras de síndrome de Down e crianças com desenvolvimento normal aos 2 e 5 anos de idade. Arquivos de Neuropsiquiatria, n. 61, v. 2B, p. 409-415. 2003.

MUSTACCHI, Z.; SALMONA, P.; MUSTACCHI, R. (org.). Trissomia 21 (síndrome de Down): nutrição, educação e saúde. São Paulo/SP. Ed. Memnon, 2017.

PAPAY, C. K.; BAMBARA, L. M. Best practices in transition to adult life for youth with intellectual disabilities. Career Development and Transition for Exceptional Individuals, v. 37, n. 3, p. 136-148, 2014.

PEREIRA, M. E. S.; BATANERO, J. M. F. Percursos educativos, formativos e profissionais na Síndrome de Down. Revista Brasileira de Educação Especial, n. 15, v. 2, p. 197-218. 2009.

PERES, L. W.; RUEDELL, A. M.; DIAMANTE, C. Influência do conceito neuroevolutivo Bobath no tônus e força muscular e atividades funcionais estáticas e dinâmicas em pacientes diparéticos espásticos após paralisia cerebral. Saúde, Santa Maria, n. 35, v. 1, p. 28-33, 2009.

QUITÉRIO, P. L. Avaliação das Habilidades Sociais de jovens com Paralisia Cerebral usuários de Comunicação Alternativa. 2009. Dissertação (Mestrado em Psicologia), Universidade do Estado do Rio de Janeiro, Faculdade de Educação, 2009.

QUITÉRIO, P. L.; NUNES, L. R. O. P.; GERK, E. Estudo preliminar: construção do inventário de habilidades sociais para alunos sem fala articulada. Revista Educação Especial, v. 33, 2020.

RIBEIRO, S. H. et al. Barriers to early identification of autism in Brazil. Revista Brasileira de Psiquiatria, São Paulo, v. 39, n. 4, p. 352-354, dez. 2017.

RODRIGUES, O. M. P. R.; SANTOS, L. H. Z.; CARLINO, F. C. Intervenção em habilidades sociais com uma criança com síndrome de Down. Revista Educação Especial, n. 27, v. 48, p. 95-110. 2014.

RODRIGUES, V.; BIANCHI, B.; AISSA, G. C.; SOUZA, S. G. P.; GALVANI, M. D. Análise do repertório de habilidades sociais de pessoas com síndrome de Down. Revista Educação Especial, v. 32, 2019.

ROOKE, M. I.; ALMEIDA, B. R.; MEJÍA, C. F. Intervenção com famílias de pessoas com deficiência intelectual: análise da produção científica. Revista de Psicologia, Fortaleza, n. 2, v. 8, p. 92-100, jul./dez. 2017.

SENO, M. P.; GIACHETI, C. M.; MORETTI-FERREIRA, D. Linguagem narrativa e fluência na síndrome de Down. Revista CEFAC, n. 4, v. 16, jul./ago., São Paulo, 2014.

SILVA, D. C.; PAIXÃO, M. G.; VILELLA, D. V. A. L. Percepção das mães quanto à sexualidade de seu filho adolescente com síndrome de Down. Revista Ciências em Saúde, v. 6, n. 2. 2016. 
SILVA, F. P. S.; LIMA, M. A. S. R. Impacto do diagnóstico de deficiência: Paralisia Cerebral dos Filhos nas Genitoras. Revista Interfaces, n. 15, v. 5, p. 19-25, 2017.

SORESI, S., NOTA, L. A social skill trainning for persons with Down's syndrome. European Psychologist, n. 5, v. 1, p. 33-43. 2000.

SPINAZOLA, C. C.; CIA, F.; AZEVEDO, T. L.; GUALDA, D. S. Crianças com deficiência física, síndrome de Down e autismo: comparação de características familiares na perspectiva materna na realidade brasileira. Revista Brasileira Educação Especial, Marília, v. 24, n. 2, p.199-216, Abr.-Jun., 2018.

\section{Como referenciar este artigo}

LESSA, T. C. R.; GALVANI, m. D. Habilidades sociais de mães de jovens e adultos com síndrome de Down. Temas em Educ. e Saúde, Araraquara, v. 17, n. 00, e021012, 2021. eISSN 2526-3471. DOI: https://doi.org/10.26673/tes.v17i00.14809

Submetido em: $25 / 02 / 2021$

Revisões requeridas em: 12/03/2021

Aprovado em: 23/04/2021

Publicado em: 28/06/2021 